Complex interventions in midwifery care: Reflections on the design and evaluation of an algorithm for the diagnosis of labour

Dawn W. Dowding, Helen L. Cheyne, Vanora Hundley

Midwifery, October 2011, Volume 27, Issue 5, Pages 654-659. DOI:

10.1016/j.midw.2009.11.001

Author's final refereed version available from:

http://hdl.handle.net/1893/2830

NOTICE: this is the author's version of a work that was accepted for publication in Midwifery. Changes resulting from the publishing process, such as peer review, editing, corrections, structural formatting, and other quality control mechanisms may not be reflected in this document. Changes may have been made to this work since it was submitted for publication. A definitive version was subsequently published in Midwifery, [VOL 27, ISSUE 5, (2011)] DOI 10.1016/j.midw.2009.11.001 


\title{
Complex interventions in midwifery care: Reflections on the design and evaluation of an algorithm for the diagnosis of labour
}

\author{
Dawn W. Dowding, PhD, BSc (Hons), RN (Senior Lecturer in Clinical Decision Making)a,*, Helen L. \\ Cheyne, PhD, MSc, RM, RGN (Programme Director) ${ }^{\mathrm{b}}$, Vanora Hundley, PhD, MSc, BN, RGN, RN, RM \\ (Honorary Senior Lecturer, Adjunktus Professor) ${ }^{\mathrm{b}, \mathrm{c}}$ \\ a Seebohom Rowntree Building, Hull York Medical School and Department of Health Sciences, University of York, York YO10 5DD, UK \\ ${ }^{\mathrm{b}}$ NMAHP Research Unit, University of Stirling, Stirling, UK \\ ${ }^{\mathrm{c}}$ Health Sciences Faculty, Semmelweis University, Budapest, Hungary
}

\section{A R T I C L E I N F O}

Article history:

Received 22 May 2009

Received in revised form

28 September 2009

Accepted 8 November 2009

Keywords:

Complex interventions

Cluster randomised controlled trial

Decision tool

\begin{abstract}
A B S T R A C T
Randomised controlled trials are the 'gold standard' for evaluating the effectiveness of interventions in health-care settings. However, in midwifery care, many interventions are 'complex', comprising a number of different elements which may have an effect on the impact of the intervention in health-care settings. In this paper we reflect on our experience of designing and evaluating a complex intervention (a decision tool to assist with the diagnosis of labour in midwifery care), examining some of the issues that our study raises for future research in complex interventions.
\end{abstract}

(c) 2009 Elsevier Ltd. All rights reserved.

\section{Introduction}

The randomised controlled trial (RCT) as a research design remains the gold standard for testing 'what works' in health-care settings. RCTs are as applicable for testing interventions that may be delivered by nursing, midwifery and allied health professionals (NMAHPs) (such as targeted health promotion advice or a structured rehabilitation programme) as they are for testing drug therapies or new surgical techniques. NMAHP interventions are often complex, in that they are 'built up from a number of components, which may act both independently and inter-dependently' (MRC, 2000), and are often introduced into equally complex health-care environments. This complexity makes the evaluation of NMAHP interventions, using a design such as the RCT, challenging; in this paper, we reflect on our experience of designing and evaluating a complex intervention (a decision tool to assist with the diagnosis of labour in midwifery care), examining some of the issues that our study raises for future research in complex interventions.

What is a complex intervention?

Complex interventions are essentially complicated (Shiell et al., 2008). Rather than comprising a single active ingredient which may be tested (such as a single drug therapy), they are

\footnotetext{
* Corresponding author. Present address: Applied Health Research, School of Health Care, Baines Wing, University of Leeds, Leeds LS2 9UT, UK.

E-mail address: D.Dowding@leeds.ac.uk (D.W. Dowding).
}

composed of a number of different interconnected parts which form the intervention to be tested. If we use our study as an example, we developed a decision tool that could be used by midwives to assist them to identify whether or not a woman attending a labour ward was in active labour (Cheyne et al., 2008a, b). In this example, the decision tool (a paper-based algorithm) involved the midwife collecting different items of information and using this information in a structured way to reach a judgement. The success (or not) of the intervention depended on how the midwife interacted with the woman and the decision tool to inform clinical judgements and management decisions. In addition, during the main trial, which was a cluster randomised trial (CRT), the decision tool was implemented within different maternity units, each of which had its own unique organisational characteristics that influenced how the tool was used in practice. It is this combination of multifaceted interventions, plus the influence of different social and organisational contexts, which makes complex interventions methodologically challenging to evaluate (Oakley et al., 2006).

\section{Evaluating complex interventions}

To assist researchers with the process, the Medical Research Council (MRC) published a framework for the development of RCTs of complex interventions in 2000 (MRC, 2000). The framework suggested five phases in the development and implementation of a clinical trial, starting with consideration of the 
theoretical basis for the planned intervention, through paperbased modelling and pilot phases, the exploratory trial, definitive RCT and finally consideration of possible long-term implementation. The framework identified important methodological issues to be considered at each phase; for example, at the modelling and exploratory trial stages, the importance of defining the intervention and of identifying the way in which the components of the trial will work together was highlighted (MRC, 2000). Although the framework was originally presented as a linear model, it was emphasised in the document that it was not intended to be a 'stepwise' process, and that, depending on factors such as the quality of existing evidence and the type of intervention being designed, some of the preliminary phases may be unnecessary (MRC, 2000).

The framework has been highly influential and a considerable body of research has now been accumulated in the evaluation of complex interventions (e.g. Wong, 2004; Robinson et al., 2005; Byrne et al., 2006). However, the science of trial development for complex interventions is constantly changing and a number of studies have highlighted limitations of the original framework, such as the implied linearity of the original guidance, the adoption of a model based on the phases of drug trial development, and a lack of consideration of the context in which interventions are introduced (MRC, 2008). In response to these concerns, the MRC published a revised framework in 2008 (MRC, 2008). Although the original stages remain, the revised framework suggests a more flexible model of the process that gives more weight to the development and implementation phases of an evaluation, acknowledges that non-experimental methods may be necessary in some situations, and highlights the importance of including health economics and process evaluations. Including these elements in a trial ensure that researchers can provide evidence on the cost-effectiveness (as well as the clinical effectiveness) of an intervention and can facilitate the interpretation of trial results. However, their inclusion adds further complexity to the trial design, trial management and, of course, to the cost of the trial itself. There is currently no consensus on the optimum means of integrating health economics and process evaluation within a rigorous trial design, nor in interpreting the multifaceted data which result from this type of evaluation.

\section{Using the MRC framework to develop and test an algorithm for the diagnosis of labour}

The work on our study began in 2002 and we used the original MRC framework as the basis for our study development. In the following section, we briefly describe our approach and the challenges we faced as the study evolved from what was first anticipated to be a small study to an 'all Scotland' CRT. The full details of the design of the algorithm and the trial results have been published elsewhere (Cheyne et al., 2007, 2008a, b). Key stages of the framework and the stages of our trial are summarised in Table 1 .

\section{Background to the study}

Although superficially straightforward, deciding whether or not active labour has started has been described as one of the most difficult decisions in the care of a woman in labour (Lauzon and Hodnett, 2003). Admission of women who are not yet in active labour is common (30-45\% of admissions) (Ball et al., 1996; Janssen et al., 2003) and has important clinical and resource implications. Several studies have reported that women admitted while not yet in labour are likely to receive higher rates of medical intervention than those admitted during the active phase
Table 1

Stages of the MRC framework related to trial phases

\begin{tabular}{|c|c|c|}
\hline MRC phase & $\begin{array}{l}\text { Key points in MRC } \\
\text { framework }\end{array}$ & Aim \\
\hline $\begin{array}{l}\text { Pre-clinical } \\
\text { Theory } \\
\text { development }\end{array}$ & $\begin{array}{l}\text { Explore relevant theory } \\
\text { to ensure best choice of } \\
\text { intervention and } \\
\text { hypothesis } \\
\text { Consider design issues }\end{array}$ & $\begin{array}{l}\text { Clinical and decision- } \\
\text { making literature } \\
\text { reviews } \\
\text { Strategic design } \\
\text { development }\end{array}$ \\
\hline $\begin{array}{l}\text { Phase I } \\
\text { Modelling }\end{array}$ & $\begin{array}{l}\text { Identify components of the } \\
\text { intervention and likely } \\
\text { interactions }\end{array}$ & $\begin{array}{l}\text { Development of the } \\
\text { algorithm } \\
\text { Preliminary testing of the } \\
\text { algorithm }\end{array}$ \\
\hline $\begin{array}{l}\text { Phase II } \\
\text { Exploratory } \\
\text { trial }\end{array}$ & $\begin{array}{l}\text { Pilot outcome measures } \\
\text { and study design }\end{array}$ & $\begin{array}{l}\text { Feasibility study: to assess } \\
\text { the feasibility of } \\
\text { conducting a cluster } \\
\text { randomised trial of the use } \\
\text { of the algorithm for the } \\
\text { diagnosis of active labour } \\
\text { in term pregnancy in } \\
\text { Scotland }\end{array}$ \\
\hline $\begin{array}{l}\text { Phase III } \\
\text { Definitive } \\
\text { randomised } \\
\text { controlled } \\
\text { trial }\end{array}$ & $\begin{array}{l}\text { Conduct a randomised } \\
\text { controlled trial }\end{array}$ & $\begin{array}{l}\text { Cluster randomised trial: to } \\
\text { compare the effectiveness } \\
\text { of an algorithm for } \\
\text { diagnosis of active labour, } \\
\text { in healthy primiparous } \\
\text { women, with standard care } \\
\text { in terms of maternal and } \\
\text { neonatal outcomes }\end{array}$ \\
\hline $\begin{array}{l}\text { Phase IV } \\
\text { Long-term } \\
\text { implementa- } \\
\text { tion }\end{array}$ & $\begin{array}{l}\text { Establish long-term effects } \\
\text { of intervention }\end{array}$ & Discussed within this paper \\
\hline
\end{tabular}

MRC, Medical Research Council.

(Hemminki and Simukka, 1986; Holmes et al., 2001; Jackson et al., 2003; Klein et al., 2003).

Increasing rates of medical intervention in labour are associated with increased morbidity for mothers and babies (AnimSomuah et al., 2005; Alfirevic et al., 2006; Klein, 2006; Villar et al., 2007) and are an issue of worldwide concern (World Health Organization, 1996). Assisting midwives to accurately diagnose active labour therefore has the potential to reduce unnecessary admissions and, correspondingly, the rate of intervention in labour.

\section{Pre-clinical or theoretical phase}

We reviewed both the clinical literature on diagnosis of labour and the theoretical literature on judgement and decision making in health care. The clinical literature indicated that there was considerable uncertainty about the timing and onset of labour, but that there was some agreement about the diagnostic cues for identifying active labour (Cheyne et al., 2006). A Cochrane review found one RCT of the use of strict diagnostic criteria for active labour which showed a reduction in interventions such as oxytocin use (McNiven et al., 1998). However, the study was under-powered and carried out in one labour ward in one country (Canada), so the evidence for the effectiveness of the intervention was limited. The process of diagnosis of labour can be considered as a judgement process, involving the evaluation of information in order to reach an assessment of the individual (in this case, an evaluation of various cues to determine whether or not a woman is in active labour) (Cheyne et al., 2006). The theoretical literature suggests that in making decisions in conditions of uncertainty, people may rely on intuition or heuristic-based decisions which 
are prone to error (Thompson, 2002). Using linear decision rules or decision support tools has been shown to increase diagnostic accuracy by encouraging the consistent use of relevant information in the diagnostic process (Garg et al., 2005; Kawamoto et al., 2005).

In summary, therefore, it was apparent that a decision tool may be a useful approach to assisting midwives with the diagnosis of labour in women. A previous RCT had indicated that it could lead to positive outcomes, and theoretically there was support for such an approach to improve diagnostic decision making. Having made a tentative decision, we then carried out a needs assessment, involving informal contacts with senior clinical midwives to both assess the magnitude of the problem (women in early labour being admitted to labour ward) and whether or not our potential solution would be acceptable in practice (Cheyne et al., 2006). This had the benefit of ensuring that we had clinical support for our study; however, it also raised awareness of the issue in maternity units (and therefore there was a danger that practice would start to change before the study was conducted).

\section{Phase 1 or modelling}

An algorithm was drafted based on the formal and informal information gathered. The MRC framework highlights the importance of developing an understanding of the intervention, identifying the active ingredients and possible effects. We used focus groups with midwives to assess the content validity of the algorithm, to gain further understanding of the way in which midwives diagnose labour, and to explore additional contextual factors for labour diagnosis and management (Cheyne et al., 2006). The algorithm was then tested for face and content validity and inter-rater reliability using questionnaires and vignettes (Cheyne et al., 2008a, b). Although this implies a linear process, in practice, the process was more interactive in nature, with the data from the focus groups, vignettes and questionnaires all informing each other.

At this point, we also needed to make a commitment to our subsequent trial design; a requirement in order to develop funding applications for the study. As the algorithm was aimed at the clinical practice of midwives, individual randomisation of women or midwives could not be used because of the risk of contamination between groups. Therefore, a CRT was required. In a cluster trial, the unit of randomisation is a group (in this case, maternity units) rather than an individual. A trial protocol was developed including decisions about study outcomes. On the basis of the initial literature review, we decided to opt for objective clinical outcomes focused on the reduction of intervention, in particular use of oxytocin for augmentation of labour, other medical interventions such as the number of admissions prior to labour, duration of labour and birth outcomes for mother and infant. These decisions allowed preliminary statistical estimates to be made.

\section{Phase II or exploratory trial}

We conducted a national survey of maternity units across Scotland to collect baseline clinical data and assess likely recruitment to the CRT. We then conducted a feasibility study in two maternity units. One issue that we needed to consider here was whether including units in the same area (Scotland) as the main trial had the potential to contaminate our eventual study findings or reduce the number of clusters which would be available for the main trial to the point where the trial would become unfeasible. On discussion, we felt that the maternity units were sufficiently independent that the risk of contamination (e.g. by midwives working across different units) was small. The objectives at this stage were: to gather accurate clinical data to inform the power calculation for the subsequent CRT; to identify midwifery units in Scotland willing to participate in a main trial; to pilot an implementation strategy for the trial; to pilot the study methods, particularly methods for gaining consent, data collection instruments, identification of eligible women and recruitment rates; and to assess the acceptability of the algorithm with midwives and to identify training needs. Following feedback from both the funding body and the ethics committee, we decided not to include a control group in the feasibility study. However, in retrospect, this was a mistake, as in the later trial we encountered unanticipated difficulties with our recruitment strategy in control sites.

\section{Phase III or main trial}

The feasibility study provided information about the implementation of the algorithm which could be used to revisit the design of our main trial. We developed successful training and implementation strategies for midwives, and consent procedures for women. However, there were also issues to be addressed before we commenced the main study. Study compliance varied between units in the feasibility study and this had to be fully investigated. We identified that the way a unit was organised and the individuals who were appointed to be local study coordinators were important issues for compliance with the study protocols. A Scotland-wide collection of baseline data demonstrated that our initial sample size calculations were inaccurate and needed to be revised. The solution to this involved collecting information on outcome measures both before and after the intervention was introduced across all the cluster sites; a methodological innovation for cluster trial sample size calculation.

It was apparent from the feedback from the feasibility study that the introduction of the algorithm might have an impact on the women taking part in the study (especially if they were sent home). Results from the focus groups had indicated that there were a number of contextual factors involved in the midwives' decision making, in particular the experience of the woman and her family. Therefore, to assess the impact on women, we developed a mixed method evaluation within the main trial which had a number of components. We invited a health economist to join the research team, who developed a discrete choice experiment to evaluate economic costs to women of taking part in the study, together with an analysis of the costeffectiveness of the intervention. In order to assess the impact of the intervention on women, we asked women who were discharged after being told they were not in labour to keep a diary of their experiences.

A key point to make is that by this stage, the study process can become very intricate with the main trial as well as parallel and related work. It is complicated to conduct from a trial management perspective and also in terms of keeping clinicians on board. For many years, it has been recognised that the process of conducting research has an effect on the research site (the Hawthorn effect) (Braunholtz et al., 2001). In the experimental site, the aim is to introduce the intervention to be tested and cause the minimum of extraneous disruption while carrying out essential observation. In the control site, the aim is to change nothing. Therefore, it can be a difficult balancing act to determine what data it is essential to collect without the process of collecting data becoming an intervention in itself.

The CRT was carried out between April 2005 and June 2007. The trial involved 14 of the 15 eligible maternity units in Scotland, who were randomised either to the experimental group (where 
the algorithm was used to assist midwives to diagnose active labour) or the control group (in which midwives, continued with their normal labour assessment processes). Overall data were collected for 4503 women giving birth for the first time. The seven experimental clusters collected data from a baseline sample of 1029 women and a post-implementation sample of 896 women. The seven control clusters had a baseline sample of 1291 women and a post-implementation sample of 1287 women.

The results of the trial found that the use of our algorithm had no significant effect on oxytocin use or medical interventions in spontaneous labour (Table 2 and Fig. 1). More women in the units where midwives were using the algorithm were discharged home following their first visit to the labour ward; however, women quickly returned to the hospital and there was no difference in the overall amount of time that women actually spent in the labour ward. There was no difference in National Health Service (NHS) costs but because women in the experimental group were higher likely to have multiple visits to the labour ward, they incurred higher travel costs as a result of the study intervention (Cheyne et al., 2008b).

\section{Implications: a complex intervention in a complex system}

The overall duration of our study, from inception through to completion of the main trial, took more than six years. We successfully developed and evaluated the decision tool; however, the final results from the main trial were both complex and difficult to interpret. Whilst this study was being carried out, several developments in the design of complex intervention trials, and the theoretical underpinnings of understanding complex intervention implementation occurred (including the publication of the revised MRC guidelines). In the remainder of this paper, we discuss our study in the light of these more recent developments of our understanding of the evaluation of complex interventions.

As already discussed, a complex intervention can be considered as a 'complicated' intervention (Shiell et al., 2008). However, we became increasingly aware, as our study progressed, that through using the MRC framework, we may have tried to make the intervention a simple one (to be tested rather like a drug treatment) rather than evaluating it as a truly complex intervention. As Shiell et al. (2008) point out, complexity in health care can have two meanings; one in relation to the property of the intervention (as described by the MRC framework) and one in relation to the properties of the systems in which the intervention

Table 2

Oxytocin use before and after trial implementation.

\begin{tabular}{lc}
\hline Oxytocin use before & Oxytocin use after \\
\hline Control units & \\
34.8 & 35.5 \\
47.7 & 48.2 \\
29.1 & 30.0 \\
37.0 & 41.0 \\
30.2 & 34.5 \\
19.8 & 36.0 \\
34.4 & 42.5 \\
Experimental units & \\
18.2 & 41.0 \\
33.3 & 31.3 \\
19.3 & 14.3 \\
40.1 & 33.7 \\
36.5 & 33.3 \\
34.6 & 52.5 \\
33.1 & 36.3 \\
\hline
\end{tabular}

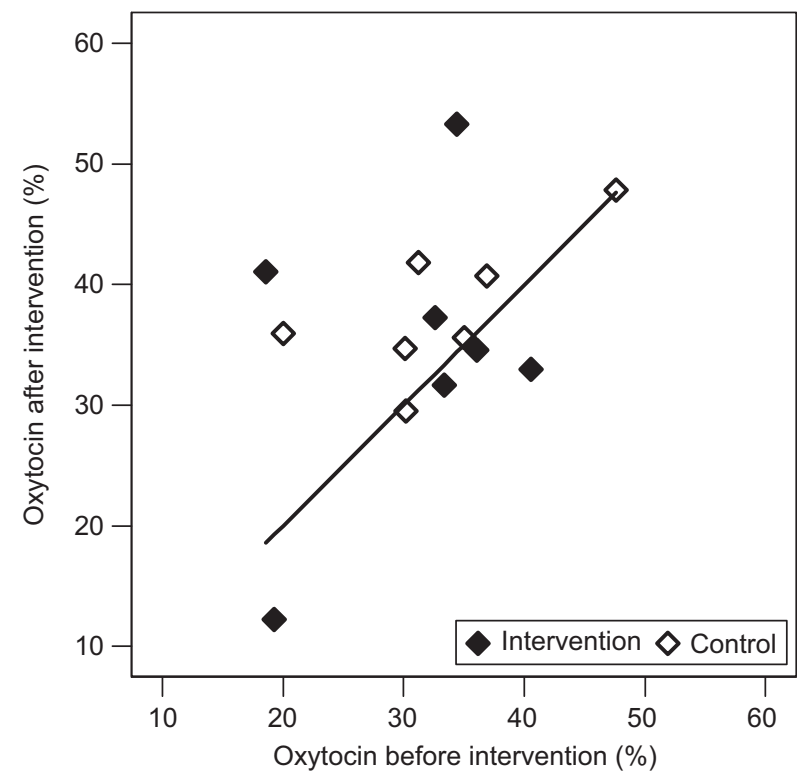

Fig. 1. Oxytocin use before and after trial implementation (adapted from Cheyne et al., 2008b).

is implemented. In this understanding of complexity, a complex system is 'one that is adaptive to changes in its local environment, is composed of other complex systems (for example, the human body), and behaves in a non-linear fashion (change in outcome is not proportional to change in input)' (Shiell et al., 2008). In essence in our trial, we were implementing our complex intervention (the algorithm) into seven complex systems (each of the maternity units in the intervention side of the trial). Meanwhile, a further seven control sites were not using the algorithm but were changing in response to a range of normal NHS organisational factors outwith the control of the study.

Complex systems have 'fuzzy boundaries', where individuals who operate within the system have the freedom to behave in unpredictable ways, who inter-connect with each other, and who have a number of internalised rules and patterns of behaviour (Rowlands et al., 2005). When a complex intervention is introduced into complex systems therefore, an interaction is likely to occur where the intervention affects both individuals and their work processes in unpredictable ways. This, in turn, may impact on the outcomes of the intervention, and may lead to the same intervention producing different results in each system in which it is introduced. In our main trial, more women in the intervention group were sent home (which could be a predictable consequence of using the tool). However, this did not lead to the expected reduction in the time spent in the labour ward, or the reduction of interventions overall. Also, the results for individual units varied (see Table 2 and Fig. 1); in some units, the intervention rate went up after our tool was introduced, whereas in others, it went down (highlighting the importance of using a cluster trial approach). In other words, there was no predictable consequence of the introduction of the decision tool across maternity units.

A number of factors, besides the use of explicit criteria to identify the presence or absence of active labour, impact on whether or not a woman is admitted into the labour ward. These include issues such as how well a woman appears to be coping with her current levels of pain, the amount of social support she may have if she is sent home, the woman's expectations about her labour, how midwifery care is organised, and institutional factors such as the availability of staff or beds (Cheyne et al., 2006). There were other factors that may also have impacted on whether or 
how the algorithm may have been used in practice, such as the organisation of the labour ward itself, who was responsible for assisting with the study in the local areas, and possibly the experience and expertise of the midwife (Dowding et al., 2009). It is likely that all of these factors will interact in different ways in each of the seven midwifery units where the algorithm was introduced; through introducing the algorithm, we will have altered some of the relationships between influential factors and impacted on different work flow processes. This, in turn, could lead to the tool having a different effect on outcomes in each of the maternity units in the experimental arm of the trial.

There are a number of changes to the revised version of the MRC framework, emphasising the non-linear nature of the development of complex interventions and highlighting the benefits of carrying out a process evaluation as part of the main trial phase (MRC, 2008). Rather than focusing on outcomes, process evaluations explore factors that may impact on the trial results. This could be an examination of how the intervention was implemented in different trial sites, how different participants viewed the intervention or how an intervention was made to 'fit' into existing work practices within trial sites (Oakley et al., 2006). In our study, in retrospect, there are a number of changes we could have made that would have both enhanced the study design and assisted with the interpretation of the trial results. Firstly, the need to incorporate an evaluation of women's experiences of the intervention suggests that it would have been useful to have had a more comprehensive evaluation, at the feasibility stage, of how the intervention affected women as this would have assisted with the design of the intervention. Secondly, it would have been useful to have explored in more detail exactly how the decision tool was used in practice by midwives in the experimental sites, and the impact it had on the way they organised their work in the labour ward. Thirdly, given that midwifery units operate within a broader organisational framework within their NHS trusts and the wider NHS, it would also have been beneficial to document changes happening at local organisational level and national level for the duration of the trial. Such data could then assist with the interpretation of complex study results, such as those obtained in our study. Future research in midwifery that uses complex interventions needs to consider incorporating an evaluation of the impact of the intervention within the complex systems in which they are implemented, as this is more likely to provide insights into the eventual benefits/limitations of any intervention and its potential impacts on more objective patient outcomes.

\section{Implications of the study for our understanding of the diagnosis of labour}

Having completed the evaluation of our algorithm, we can reflect on the implications of our results for understanding issues surrounding the identification and management of women in the latent or active stages of labour. The introduction of algorithms, such as the one in this study, has been shown to increase the accuracy of clinicians' diagnosis (Meehl, 1954; Grove et al., 2000; Dawes et al., 2002; Garg et al., 2005; Kawamoto et al., 2005). The process of designing and evaluating the algorithm discussed here indicated that the algorithm could be used consistently by midwives, and was valid, acceptable and easy to complete (Cheyne et al., 2008a, b). The trial results indicated that it did have some effect on midwives' judgements; women in the intervention group who were assessed with the aid of the algorithm in the early stages of labour were significantly more likely to be sent home (Cheyne et al., 2008b). However, these women were also likely to return immediately, creating a 'revolving door' effect, with very little impact on subsequent interventions that they may have received. In essence, what appeared to be happening on the basis of our study intervention was that the algorithm had an effect on midwives' diagnosis of labour, but very little effect on the management decisions that were taken when a woman was finally admitted to the labour ward.

Much of the literature discussing issues of diagnosis of labour and the link between admission in the latent phase of labour and increased intervention, suggests that if the women were not in the labour ward in the first place, the number of interventions would decrease. However, the issues that have arisen on the basis of our study suggest that the picture may be more complex than this.

First, simply sending a woman home because she is not in active labour does not recognise the reasons why she may have attended the labour ward in the first place (Cheyne et al., 2007). Women often attend the labour ward because they are anxious about being at home and are finding their current levels of pain difficult to cope with (Cheyne et al., 2007; Barnett et al., 2008). Without recognising these issues and providing some form of support to women (either in a designated area within the midwifery unit or in their own home), any intervention to try and reduce a woman's likelihood of re-attending the labour suite will encounter difficulties.

Second, it may be too simplistic to suggest that a woman is more likely to encounter interventions just because she has been admitted to the labour ward. Our study results highlight that there was little difference in the number of interventions (or length of labour) between women sent home repeatedly and those admitted straight away into the labour ward. This would suggest that the focus of study may need to shift to examining the decisions that midwives take when caring for women in labour; both in terms of the decisions that are taken and the information on which they are based. In contrast to judgements, decisions can be considered to be 'choices between alternatives' (Dowie, 1993), and should ideally be based on some form of evaluation of the risks and benefits of each of the alternative actions available to an individual. There is very little research examining how midwives reach decisions about interventions with women during labour. Our results suggest that this may be a more fruitful area of study if we wish to reduce the number of interventions that women receive, as it is possibly this part of the decision process (rather than a midwife's ability to accurately identify women in labour in the first place) which is contributing to higher intervention rates.

\section{Acknowledgements}

The work discussed in this paper was funded by a grant from the Chief Scientist Office, Scottish Government (ref: CZH/4/245). The views expressed here are those of the authors and not of the Chief Scientist Office. We would also like to thank the midwives and women who took part in the study and Carol Barnett and Maggie Styles who assisted with data collection and trial management.

\section{References}

Alfirevic, Z., Devane, D., Gyte, G.M.L., 2006. Continuous cardiotocography (CTG) as a form of electronic fetal monitoring (EFM) for fetal assessment during labour. Cochrane Database of Systematic Reviews, Article no. CD006066, doi: 10.1002/14651858.CD000331.pub2.

Anim-Somuah, M., Smyth, R., Howell, C., 2005. Epidural versus non-epidural or no analgesia in labour. Cochrane Database of Systematic Reviews, Article no. CD000331, doi: 10.1002/14651858.CD000331.pub2.

Ball, J.A., Washbrook, M.A., 1996. Birthrate Plus Framework for Workforce Planning and Decision Making for Midwifery Services. Books for Midwives Press, London.

Barnett, C., Hundley, V., Cheyne, H., Kane, F., 2008. Not in labour: impact of sending women home in the latent phase. British Journal of Midwifery 16, 144-153. 
Braunholtz, DA, Edwards, SJ, Lilford, RJ., 2001. Are randomized clinical trials good for us (in the short term)? Evidence for a 'trial effect'. Journal of Clinical Epidemiology 54, 217-224.

Byrne, M, Cupples, ME, Smith, SM, et al., 2006. Development of a complex intervention for secondary prevention of coronary heart disease in primary care using the UK Medical Research Council framework. American Journal of Managed Care 12, 261-266.

Cheyne, H, Dowding, D, Hundley, V., 2006. Midwives' diagnostic judgement and management decisions in making the diagnosis of labour. Journal of Advanced Nursing 53, 625-635.

Cheyne, H, Dowding, D, Hundley, V, et al., 2008a. The development and testing of an algorithm for diagnosis of active labour in primiparous women. Midwifery 24, 199-213.

Cheyne, H, Hundley, V, Dowding, D, et al., 2008b. The effects of an algorithm for diagnosis of active labour: a cluster randomised trial. British Medical Journal 337, a2396

Cheyne, H, Terry, R, Niven, C, Dowding, D, Hundley, V, McNamee, P., 2007. 'Should I come in now?' A study of women's early labour experiences. British Journal of Midwifery 15, 604-609.

Dawes, RM, Faust, D, Meehl, PE., 2002. Clinical versus actuarial judgement. In: Gilovich, T, Griffin, D, Kahneman, D. (Eds.), Heuristics and Biases: The Psychology of Intuitive Judgement. Cambridge University Press, Cambridge, pp. 716-729.

Dowding, D, Mitchell, N, Randell, R, Foster, R, Lattimer, V, Thompson, C., 2009. Nurses' use of computerised clinical decisions support systems: a case site analysis. Journal of Clinical Nursing 18, 1159-1167.

Dowie, J., 1993. Clinical decision analysis: background and introduction. In: Llewelyn, H., Hopkins, A., (Eds.), Analysing How we Reach Clinical Decisions. Royal College of Physicians, London.

Garg, AX, Adhikari, NKJ, McDonald, H, et al., 2005. Effects of computerized clinical decision support systems on practitioner performance and patient outcomes. A systematic review. Journal of American Medical Association 293, 1223-1238.

Grove, M, Zald, DH, Lebow, BS, Snitz, BE, Nelson, C., 2000. Clinical versus mechanical prediction: a meta-analysis. Psychological Assessment 12, 19-30.

Hemminki, E, Simukka, R., 1986. The timing of hospital admission and progress of labour. European Journal of Obstetrics, Gynecology, and Reproductive Biology $22,85-94$

Holmes, P, Oppenheimer, LW, Wen, SW., 2001. The relationship between cervical dilatation at initial presentation in labour and subsequent intervention. British Journal of Obstetrics and Gynaecology 108, 1120-1124.

Jackson, DJ, Lang, JM, Ecker, J, Swartz, WH, Heeren, T., 2003. Impact of collaborative management and early admission in labour on method of delivery. JOGN Nursing 32, 147-157.

Janssen, P, Iker, C, Carty, E., 2003. Early labour assessment and support at home: a randomised controlled trial. Journal of Obstetrics and Gynaecology Canada 25, 734-741.
Kawamoto, K, Houlihan, CA, Balas, EA, Lobach, DF., 2005. Improving clinica practice using clinical decision support systems: a systematic review of trials to identify features critical to success. British Medical Journal 330, $765-768$.

Klein, M.C., 2006. Epidural analgesia: does it or doesn't it? Birth 33, 74-76.

Klein, MC, Kelly, A, Kaczorowski, J, Grzybowski, S., 2003. The effect of family physician timing of maternal admission on proceedures in labour and maternal and infant morbidity. Journal of Obstetrics and Gynaecology Canada 26, 641-645.

Lauzon, L, Hodnett, E., 2003. Labour assessment programs to delay admission to labour wards (Cochrane Review) In: The Cochrane Library, Issue 1. Update Software, Oxford.

Meehl, PE., 1954. Clinical Versus Statistical Prediction: a Theoretical Analysis and Review of the Evidence. University of Minnesota Press, Minneapolis.

McNiven, PS, Williams, JI, Hodnett, E, Kaufman, K, Hannah, ME., 1998. An early labor assessment program: a randomized, controlled trial. Birth 25, 5-10.

Medical Research Council (MRC), 2000. A Framework for Development and Evaluation of RCTs for Complex Interventions to Improve Health. Medical Research Council, London.

Medical Research Council, 2008. Developing and Evaluating Complex Interventions: New Guidance. Medical Research Council, London.

Oakley, A, Strange, V, Bonell, C, Allen, E, Stephenson, J, 2006. Process evaluation in randomised controlled trials of complex interventions. British Medical Journal 332, 413-416.

Robinson, L, Francis, J, James, P, Tindle, N, Greenwell, K, Rodgers, H., 2005. Caring for carers of people with stroke: developing a complex intervention following the Medical Research Council framework. Clinical Rehabilitation 19, 560-571.

Rowlands, G., Sims, J., Kerry, S., 2005. A lesson learnt: the importance of modelling in randomized controlled trials for complex interventions in primary care. Family Practice 22, 132-139.

Shiell, A, Hawe, P, Gold, L., 2008. Complex interventions or complex systems? Implications for health economic evaluation. British Medical Journal 336 1281-1283.

Thompson, C., 2002. Human error, bias, decision making and judgement in nursing - the need for a systematic approach. In: Thompson, C, Dowding, D (Eds.), Clinical Decision Making and Judgement in Nursing. Churchill Livingstone, Edinburgh, pp. 21-45.

Villar, J., Carroli, G., Zavaleta, N., et al., 2007. World Health Organization 2005 Global survey on maternal and perinatal health research group, 2007 Maternal and neonatal individual risks and benefits associated with caesarean delivery: a multicentre prospective study. British Medical Journal 335, 1025 , Epub 2007 October 30

Wong, IC, 2004. Randomised controlled trials (RCTs) to evaluation complex healthcare interventions - a case study. Pharmacy World and Science 26, 247-252.

World Health Organization, (WHO), 1996. Care in normal birth: a practical guide. In: Safe Motherhood. WHO, Geneva, (Chapter 1). 